\title{
James Salter's Pilots and Wingmen, Then and Now
}

\author{
David Kirk Vaughan \\ Air Force Institute of Technology, Dayton OH, USA
}

\begin{abstract}
This essay examines the stylistic changes James Salter made when he revised his first two published novels, The Hunters (1956) and Arm of Flesh (1960). Examination of the revised versions, The Hunters (revised, 1997) and Cassada (2000) shows that changes made in The Hunters are primarily minor stylistic changes designed to improve visual and narrative clarity, while the revisions in Arm of Flesh/Cassada are more substantial, bringing the central character into clearer focus and making the events of the novel more accessible to non-military readers.
\end{abstract}

Keywords: Air Force novel, modern novel, aviation, Korean War, Cold War

\section{Introduction}

James Salter's first two novels describe the lives of Air Force fighter pilots in the Korean War and in Cold War Europe. The Hunters was based on Salter's experiences as a pilot in the Korean War; it was serialized in Collier's magazine early in 1956, and adapted as a film which starred Robert Mitchum and Robert Wagner. Arm of Flesh (1961) appeared five years after The Hunters and describes events involving a fighter squadron which flies training missions in Europe and North Africa. It was not made into a film. This paper compares the original and revised versions of both novels to determine what changes were made and why Salter might have decided to revise them.

James Salter (originally James Arnold Horowitz; he changed his name in 1962) is probably best known for his film script Downhill Racer, which starred Robert Redford, and for his erotic novel A Sport and a Pastime (1967). His other novels of note include Light Years (1975) and Solo Faces (1979). Before establishing himself as a writer, however, he was a pilot in the U. S. Air Force; he graduated from West Point during World War II and flew a variety of aircraft before flying jet aircraft in the Korean War and later in Europe. After the commercial success of his first novel, The Hunters (1956), Salter left the Air Force to devote himself to writing. After the success of his later novels, especially Solo Faces, a novel about mountain climbing in Europe, Salter tended to disparage the quality of his first two novels, calling them apprenticeship works (Dowie, 1988, p. 77). They may well be apprenticeship works for a serious writer, but they are also two of the best novels written about the life of a jet fighter pilot in the 1950s and 1960s. He thought enough of them to rewrite them many years later. The Hunters was revised and re-published in 1997, 40 years after its original appearance. Arm of Flesh was revised, re-titled (Cassada), and re-published in 2000, 39 years after it first appeared.

The Hunters accurately describes the U. S. Air Force fighter experience in the Korean War. The war in the air over Korea had its own timeline, its own cycle of action, relatively unrelated to any action occurring on the ground. The Korean War began in 1950 and ended in 1953, as the ground forces of the North Koreans, with the help of the Chinese army, first pushed the American and allied forces down to the tip of the Korean peninsula, 
and then fell back as the American army, under General Douglas MacArthur, pushed them to the Yalu River, the line separating North Korea from China. For the first two years of the war, it was fought in the air by aircraft of World War II vintage, P-51s, B-26s, and B-29s, aircraft with reciprocating engines, with similar if less capable aircraft flown by the North Koreans. Then the Russians brought a revolutionary jet aircraft into the conflict, the MiG-15. It was a high-performance, high-altitude aircraft that could fly as high as 50,000 feet, an altitude no American aircraft could reach. When the MiG-15 appeared late in 1950, the U. S. Air Force found itself at a decided disadvantage in the air. To counter the Mig-15, the F-86 was rushed into production and sent to Korea before its pilots really knew much about its performance characteristics. The war in the air changed noticeably in 1952 and 1953, when the flights of F-86s encountered flights of MiG-15s. The F-86s had to fly north from airfields in the vicinity of Seoul, South Korea, to the Yalu River, the boundary between North Korea and Russia, a flight of some 200 miles that left little time to loiter over North Korean territory. The MiGs, on the other hand, had only to take off and climb to altitude over their field to encounter the American pilots. They often chose not to do so, but when they did, it was in greater numbers than the Americans could produce. We now know that the best pilots flying for the North Korean Air Force were Russian pilots, sent to ensure the success (and longevity, probably) of the Russian-built MiGs. Because of their lighter weight, the MiG-15s could fly to higher altitudes than the heavier F-86s.

It was a new kind of combat experience, with aircraft circling at altitudes between 40 and 50 thousand feet; at these altitudes the air is thin, and aircraft, even jet aircraft, have to maneuver very carefully, slowly, and cautiously. If they try to maneuver too abruptly, by making a hard banking turn, the kind that could be safely accomplished at 30 thousand feet or below, they could stall and enter a spin, from which they might or might not recover. Maneuvering to engage the enemy was a slow, time-consuming process, in which pilots on both sides tried to cut opposing aircraft off in large, circling turns, and then, when they judged themselves close enough, raise the nose of their aircraft, fire a few well-aimed shots, and hope to inflict some damage on the other aircraft. If the high altitude pattern could be disrupted, then the entire set of formations might drop down to lower altitudes, where more traditional, more intense aerial combat might take place, with two-ship flights maneuvering to catch an enemy aircraft off guard. The two-ship formation was essential for survival, as the pilot in the second ship, the wingman, kept an eye out for an approaching hostile aircraft while the leader, the pilot in the lead ship, looked for an aircraft to attack. The wingman's job was to stay on his leader's wing. The two-man team effort was essential for success.

New pilots joining a fighter squadron thus had to learn to fly in the thinner air above 40 thousand feet, to maneuver carefully but purposefully, and not put themselves at risk unnecessarily. They had to be able to judge the speed and intentions of opposing aircraft. They had to be able to manage their own weapons systems, the machine guns or cannons, which fired on an intercept calculated by their cockpit instruments. They had to have the nerve to place themselves in vulnerable positions if they wanted to draw an opposing aircraft into combat. Physically and mentally, flying in combat along the Yalu River, also known as "MiG Alley", was extremely challenging.

This is the operational world of The Hunters. The central character is Cleve Saville, an experienced pilot who, like Salter, had flown during World War II, but who had not yet flown in Korea. When he arrives in Korea, he is placed in a wing (a wing consists of two or more squadrons) commanded by an old friend and acquaintance before the war, Colonel Imil. Imil expects Cleve to become one of his squadron's star performers, but Cleve initially does not have success in combat. The Wing Commander's attitude is that it is the mark of a 
good pilot to have shot down a MiG; a great pilot would shoot down five and thus become an "ace", an aerial mark of distinction that had been established during World War I and continued in World War II.

Saville is given command of a flight in the squadron. A flight consisted of five or six men who flew in formation into and out of combat. Initially Saville is comfortable training the other pilots, about half of whom are new, in the techniques and procedures of combat operations, of which Saville is still learning the finer points himself.

Then a new pilot arrives, Pell, a first lieutenant who likes to refer to himself as "the Doctor", and whose brash nerve, slightly contemptuous attitude, and aerial competence immediately annoy Saville. Pell is a good pilot but he does not really like to fly in a wingman's position, to which his relatively junior rank relegates him, and he often finds an excuse for separating himself from his leader when a combat opportunity occurs. Pell soon starts shooting down MiGs. Saville is infuriated by Pell's go-it-alone attitude, but because Pell is the only pilot in the flight with any victories, the Wing Commander is willing to overlook his individualistic tendencies and even indirectly encourages him in his efforts. Finally, when Pell deserts his leader for the third time to pursue a MiG on his own, Saville loses his temper and takes a swing at Pell. They are quickly separated, but the Wing Commander supports Pell. Later, when Colonel Imil attempts a reconciliation with Saville, Saville rejects the offer and loses Imil's friendship. The novel concludes when Saville, after having shot down the top enemy pilot, “Casey Jones”, so-called because he leads “trains” of MiGs through the sky, is himself killed in combat.

The novel depicts not only the external world of aerial combat above 40 thousand feet, but also the internal world of squadron and wing politics: the sly denigration of pilots too hesitant to engage with the enemy; the efforts of pilots who have shot down enemy aircraft and embellish their accounts of aerial combat to build their personal reputations; the persuasive powers of the wing commander to persuade one pilot to agree that he has seen an enemy aircraft destroyed by his flight leader when he had not actually done so; and, in one wonderful scene, the efforts of one pilot to rewrite his narrative to ensure that he receives the highest medal possible. Salter, having been a fighter pilot himself, accurately describes the competitiveness between pilots and groups of pilots that is characteristic of a fighter squadron.

In his re-written version of The Hunters, Salter makes two kinds of changes: names and descriptive details. He adds a Preface in which he gives some contextual background for modern readers that (probably) wouldn't have been necessary in 1956, three years after the Korean War ended. But now all the aircraft that flew in Korea exist in museums only, so the additional information is helpful. It is not clear why Salter felt the need to change the names: a squadron commander's name is changed from Ausman to Desmond. A fighter pilot named Sheedy is now Robey. Salter changes the name of the main character from Cleve Saville to Cleve Connell. Connell was the name of an American ace during the Korean War, who later died in an aircraft accident. But in the novel Cleve is not an ace. Another puzzling name change Salter makes is to change the name of Cleve's primary flying partner from Corona to DeLeo. One name Salter does not change is the name of the annoying American pilot, Pell. Those who knew something of Salter's flying background in the Korean War knew that the character of Pell was based on a pilot by the name of James Kasler, an obnoxious, aggressive pilot who was credited with shooting down six enemy aircraft and who flew Salter's wing for a period of time during the war. Kasler later flew in the Vietnam conflict where he was shot down and became a prisoner of war. But the details of Pell's character and behavior remain unchanged in the revised version.

The more substantive changes in The Hunters are small but helpful stylistic changes. To give an example of Salter's stylistic changes: in the original version, this is how Salter describes the return of the aircraft after 
one mission:

When the ships returned from a mission, everybody watched for them. Usually, they came lining back to the field in flights of four, flying tight show formation with the black smoke fading in parallel streams behind as they turned in toward the runway and landing pattern. They seemed to be most indestructible then. They were of frozen silver. Nothing could possibly befall that grace. No enemy could deny them. Departures were stirring; but every return, even the most uneventful, was somehow triumphant and a call to the heart to rise in joy. Out of the north they had come again, brief regiments of splendor. (Salter, 1956, p. 69)

This is the revised version:

When the ships returned from a mission, everybody watched for them. Usually, they came lining back to the field in flights of four, flying tight show formation with the black smoke fading in parallel streams behind as they turned in toward the runway and landing pattern. They seemed to be most indestructible then. They were of frozen silver. Nothing could possibly dim that grace. No enemy could deny them. Departures were stirring; but every return, even the most uneventful, was somehow transcendent and a call to the heart to rise in joy. Out of the north they had come again, brief strokes of splendor. (Salter, 1997, p. 69)

The three small stylistic changes in this paragraph show Salter correcting or modifying aspects of the description: to befall grace is awkward; to dim grace is better; transcendent is much better than triumphant; the third fix, substituting strokes for regiments, is as much an improvement of logic as style.

One more example:

Cleve Saville has just shot down his first MiG; his wingman, following on his wing, has been watching out for enemy aircraft. In the original version, this follows:

“Did you see that, Billy?” he shouted.

"Break Left!"

Cleve turned hard, straining to look back. Two MiGs, firing, swept close behind and then climbed away. They did not come back. They kept going until they were out of sight in the direction of the river. (Salter, 1956, p. 86)

And this is the revised version:

“Did you see that, Billy?” he shouted.

"Break left!"

Cleve turned hard, straining to look back. Two MiGs, firing, sat close behind. Their noses were alight. He was turning as hard as he could, not gaining, not yet feeling himself hit, thinking no, no, when the last moment they were gone, climbing away, in the direction of the river. (Salter, 1997, p. 85)

In both versions, the number of sentences remains the same, yet the impact of the second version is much more immediate, more visceral. In the revised version we can more easily share Cleve's profound worry that he might himself be shot down within a few seconds of his first victory. The image of the MiG noses "alight", bright visual evidence of their guns firing at him, missing from the original version, makes this incident much more effective in the revised version.

Not counting name changes, there are approximately forty relatively minor stylistic changes, all designed to clarify the narrative. They are the kinds of changes that a knowledgeable editor might make. In general, the results of his stylistic changes show his concern for what it looked like, flying in the skies over Korea. The most important of his changes have to do with enhancing the visual aspects of his descriptions.

The sense of fighter pilot politics that appears in The Hunters continues in an even more intense form in his 1961 novel, Arm of Flesh. This novel takes place in Europe in the late 1950s, as the fighter aircraft and the 
pilots who flew them are located on North Atlantic Treaty Organization bases in France and Germany, where their presence demonstrates the allied determination to resist any efforts by the Soviet bloc to invade Western Europe; Germany at that time was divided into eastern and western halves. One American squadron flying jet aircraft (probably F-84 aircraft; Salter never identifies specific aircraft type in either novel) is assigned to a base in France. During the course of the novel we see the men involved in "scrambles" to intercept possible hostile aircraft; this duty is interrupted for a period of time in which they fly to an American base in Libya, North Africa, where they participate in gunnery training, shooting at targets towed by other aircraft (this process is particularly well-described in the novel).

The main conflict in the novel occurs when a new pilot, named Cassada, arrives in the squadron. In addition to being recently trained, he is junior in rank, a bit of a dreamer, and compared to the other men, at least, slow to learn operational procedures. He prefers to drink tea rather than coffee and is from Puerto Rico, a location some men in the squadron apparently believe is a foreign country. He does not fit, in other words, the image of the fighter pilot, and he pays the political price for his differentness. The squadron operations officer (the second-ranking officer in the squadron), Isbell, gradually develops an interest in Cassada and determines to give him some pointers and instruction about flying that might lead to his acceptance by the pilots of the squadron. The event that frames the novel and gives it its dramatic focus is the effort of Cassada and Isbell, each flying in his own aircraft in a two-ship formation, to land at their home field in bad weather (a situation officially known as landing in "below minimum” weather). If a field is "below minimums", pilots are supposed to divert to another field where the weather is better. But because they are low on fuel, they are unable to do so. Their predicament is especially precarious because Isbell, the more experienced pilot, and who was the flight leader when they left their original field, has experienced radio failure and has had to relinquish the lead position to Cassada. Cassada, who has many fewer hours of flying time than Isbell, makes two attempts to land in the poor weather but is unable to do so. On his final attempt, he runs out of fuel, crashes, and is killed. Isbell, who became separated from Cassada on the second approach, climbs to altitude and bails out of the aircraft. He survives. The novel concludes with a burial service at the base chapel and a flyby of aircraft displaying a missing man formation.

The novel describes the interpersonal dynamics of the men in the squadron, who display a variety of personalities and backgrounds. There is the military academy graduate, self-controlled and insistent on discipline; the easy-going joker; the older squadron commander, hoping for his next promotion; the taciturn country boy, whose language is coarse but who is a good pilot. The competitiveness among these men is evident in every episode. In one crucial episode in the book, Cassada, trying to improve his poor scores on the gunnery range in North Africa, accepts the challenge of one month's pay made by one of the most experienced men in the squadron. Cassada is determined to demonstrate his willingness to risk his reputation in an effort to be accepted in the squadron, but he loses the bet. Instead of gaining acceptance, he is further humiliated. In frustration, he throws his shoes at a light in the tent, breaking the glass.

It is at this point that Isbell begins a personal effort to assist Cassada, culminating in a return to the gunnery course in North Africa, where he shows Cassada some techniques that could help him improve his gunnery scores. They are returning from this training program when they are caught in the bad weather as they attempt to land at their home field in France.

Arm of Flesh is written in an unusual fictional format, as each of the men in squadron (thirteen in all) speak in individual narratives prefaced with their names. Although a careful reader can distinguish among their 
voices, especially the squadron commander, Clyde, the good-looking natural pilot, Grace, the unpolished country boy, Harlan, and the operations Officer, Isbell, it is difficult for a reader unfamiliar with fighter pilot phraseology to sort them out, even when each individual's name is provided. One reader commented that "there are so many speakers and so little differentiation in their speaking voices that... the characters lack both substantiality and development” (Dowie, 1988, p. 80). Evan Salter disparaged his effort in Arm of Flesh, calling it "derivative Faulkner" (Smith). The central character, Cassada, is never given his own voice, adding to the reader's sense of Cassada's alienation from the other members of the squadron. Given the fact that the book concludes with the death of Cassada, it is as if the voices of the other pilots constitute an unofficial record of the hearing that would have taken place after such an incident, in which all the pilots who knew the deceased would give their opinions of the dead pilot's capabilities and past performance in the squadron.

As a result of Salter's creative fictional technique, Arm of Flesh is a more complex novel than The Hunters. However, the novel itself was not a popular success. Salter himself called it a "failure” (Cassada, 2000, p. vii), and apologized for resurrecting it in a revised version in 2000. By renaming it Cassada, Salter appears to be compensating for slighting the central character in the original version. The major change that Salter makes in his 2000 rewrite is to tell the story in the more traditional third person narrative voice, although many of the comments and all of the incidents in the original version are included. The third person narrative form makes the plot and characterization more accessible, especially to a reader unfamiliar with Air Force terminology. Salter also develops the relationship between two central characters, Cassada and Isbell, more completely, making the thematic connection between the two characters clearer. The young novice pilot Cassada is presented as having a perspective of the world similar to that of Isbell, the one character in the story whose imagination and sense of appreciation of the world of the fighter pilot, with its danger, excitement, and spectacular beauty of in flight experience, does not seem to be shared by any other pilot in the squadron. Thus the loss of Cassada is a personal loss for Isbell as well as a professional loss, an aspect not made as clear in the original novel. The third person narrative serves to make the character of Cassada less remote, less isolated, than it is in the original version.

In contrast to the isolation of Cassada in Arm of Flesh, we know the character more intimately in Cassada and thus can share more completely his sense of failure in being rejected by the other members of the squadron. In the revised version Salter expands on Cassada's humiliation in losing the gunnery target bet when the winning pilot complains, in front of the assembled squadron, that Cassada can't pay off the complete amount of the bet (one month's pay); this detail was not in the original version. Finally, the revisions in the novel explain in more detail the special activities of a fighter squadron in Europe at the height of the Cold War, a unique picture of a world and time now lost, "the fighter bases of Europe, and the life itself” (Cassada vii).

Even with the modifications, however, the fighter pilot's experiences still remain slightly unclear for the normal (non-military) reader. It would have helped, for instance, if Salter would have given more details about the actual aircraft that he flew (the F-86s in Korea and the F-84s in Europe) to give a sense of the complex technological environment in which fighter pilots lived, to give the reader some sense of the exhilaration and occasional terror produced in the cockpit when the equipment worked as it was supposed to and when it didn't, the kind of description that Richard Bach does so well in his version of flying F-84s in Europe, Stranger to the Ground.

Salter's concern to improve, to clarify the visual images in both books points to his concern to capture accurately the lived experience of fighter pilots in Korea and Europe. Because he had been one of them, one of 
a special group of men, because he had lived the kind of life he was writing about, he apparently felt a strong urge to portray the environments of his characters as accurately as possible. This is the impulse that must have driven his concern to revise his first two novels.

\section{Conclusion}

Salter's revisions to his first novel, The Hunters, assist the reader in gaining a better visual appreciation for the experiences of the combat pilots who flew in the skies over North Korea during the Korean War, but it is not apparent how the name changes in the novel make any meaningful difference in our appreciation of the events in the story. Cassada provides a clearer story line and establishes a stronger bond between the two main characters than exist in his earlier Arm of Flesh, but at the expense of the creative conceptual framework of the original novel. In either their original or their revised versions, however, the novels remain compelling accounts of the unique worlds of the modern fighter pilot.

\section{References}

Dowie, W. (1988). A final glory: The novels of James Salter. College English, 50(1), 74-88.

Salter, J. (1956). The hunters. New York: Harper.

Salter, J. (1961). Arm of flesh. New York: Harper.

Salter, J. (1997). The hunters (Revised ed.). Washington, D.C.: Counterpoint.

Salter, J. (2000). Cassada (Revised version of Arm of Flesh). Washington, D.C.: Counterpoint.

Smith, D. (1997). Fighter pilot who aimed for fiction but lived on film [Book Review of Burning the Days]. New York Times. 